\title{
Measuring innovation capacity in the agrifood sector: from single companies to value chains
}

\author{
Bianka Kühne, Virginie Lefebvre, Bert Vermeire and Xavier Gellynck \\ Ghent University, Department Agricultural Economics, Coupure Links 653, 9000 Gent, Belgium; Bianka.Kuhne@Ugent.be
}

\begin{abstract}
This paper proposes an approach for measuring innovation in the agrifood sector. First we develop a concept of innovation taking into account its multiform, complex and embedded character. We then we evaluate the validity of the concept by applying it to single firms and value chains in the agrifood sector. This reveals that the concept works well both at firm and value chain levels. This paper provides the basis for future research in the field of innovation measurement at firm and value chain levels, providing also important implications for the further development of the proposed approach. We encourage other scholars to test the applicability of our approach to other sectors.
\end{abstract}

Keywords: concept of innovation capacity, SMEs, agrifood sector

\section{Introduction}

Over the past few decades, the concept of innovation has gained tremendous popularity in the discourse of economists, business communities and policy makers. Despite widespread agreement that innovation is a precondition for competitive and sustainable economies, there is little consensus about the definition of innovation. This is strongly related to the complex nature of the innovation process (Gellynck and Kühne, 2011).

A number of theoretical insights can be identified which have elucidated the concept of innovation, on the one hand, but also extended its breadth and depth, making it more difficult to apply, on the other. First, the conception of innovation as a simple linear and basically research-driven process has been abandoned because of the recognition that innovations are not always research driven, but sometimes generated by interactions among different actors and knowledge flows. Innovation development is no longer seen as a linear process, but as a complex process involving false starts, returns between stages, dead ends, trial and error (Rothwell, 1992; Tidd et al.; 2005, Balconi et al., 2008; Kirner et al., 2009). Second, the contribution of innovation to economic growth is not only due to radical, breakthrough innovations but also to incremental changes which take place over time (Dewar and Dutton, 1986; Lettl et al., 2006). Further, incremental changes might have breakthrough effects, e.g. a small change in the distribution of manufactured products leading to tremendous cost reduction (Omta, 2002; Antonelli, 2006). Third, innovation can be situated at the level of the product, but also at the level of production processes, organizational changes and marketing strategies (Lundvall, 1995; Fischer,
2001; Becheikh et al., 2006). Fourth, innovation always involves dilemmas, whereby the entrepreneur faces the complex task of taking a management decision under uncertainty about market demand, industry response (e.g. pricing policy, product imitation) and also production and development costs (Dawid et al., 2001; Miller, 2008). In some cases, not innovating may be the best management decision. Fifth and finally, the view on how innovation is driven has changed over time from seeing it as a supply-push to a demand-pull process. Demand-pull innovation, also called user-oriented innovation, is the effort of all actors involved in the innovation process to maximize the value creation towards the final consumers and rapidly respond to their new demands (Grunert et al., 2008; Weaver, 2008). These insights confront researchers of innovation with the fundamental dilemma of whether to narrow down the focus to a specific aspect of innovation or apply a rather holistic approach to obtain an overall understanding.

For the agrifood industry, particularly the change from supply-push towards demand-pull innovation has proven to be very important, because of the increasing number of intangible components involved in the innovation process, the rapid changes in consumer needs, and the growing demand for more sustainable production (Grunert et al., 2008). Further, fundamental changes of the last century, including the rapid development in information and communication technology and internationalization have affected all areas related to food production (Avermaete and Viaene, 2002, OECD, 2005). In response, the agrifood industry has developed strategies that are not based on $\mathrm{R} \& \mathrm{D}$ but include a learning process and interaction between different actors. Thus, the locus of innovation has increasingly shifted from the single enterprise to the value 
chain (Powell et al., 1996; Omta, 2002, 2004; Pittaway et al. 2004; Grunert et al., 2008). Previous studies have shown that companies in the agrifood sector are highly dependent on external sources of information for innovation and hence have to open up their innovation process to their value chain (Stewart-Knox and Mitchell, 2003; Avermaete et al., 2004a; Enzing et al., 2008; Sarkar and Costa, 2008). This prompts the need to develop measures which allow the evaluation of innovation both at the company and value chain level. A value chain consists at minimum of three members: the food manufacturer (FM), the supplier of the FM and the customer of the FM which is also referred to as the direct chain (Mentzer et al., 2001). These value chain members are involved in the upstream and downstream flows of products, services, finances and information in a vertical structure (Van der Vorst, 2000; Mentzer et al., 2001).

Innovation is defined here as an ongoing process of learning, searching and exploring, resulting in products, techniques, forms of organization and markets (Lundvall, 1995) which are new to the enterprise and to the industry. Innovations range from incremental to radical. The focus is thus broadened to include not only commonly investigated product and process innovations but also less-acknowledged market and organizational innovations. The former are most relevant for R\&D-intensive and high-tech industries, whereas innovation in low-tech industries and $\mathrm{SMEs}^{1}$ is often related to activities other than R\&D (Lagnevik et al., 2004; Gellynck et al., 2007; CIAA, 2009; Kirner et al., 2009).

For the measurement of innovation in SMEs it is less suitable to use indicators such as the number of patents, number of employees involved in $R \& D$, or counts of incremental and radical innovations (Avermaete and Viaene, 2002; Maravelakis et al., 2006). In particular for SMEs in the agrifood sector, which make up over $90 \%$ of the sector generally considered as a low-tech industry, other indicators for measuring innovation must be applied such as structured and non-structured efforts, new or improved products, processes, markets and organizational developments, as well as the contribution of these innovation activities to the business success (Gellynck et al., 2007).

However, there is no consistent use of the indicators in the literature. Some indicators for measuring innovation are also used to measure other concepts, such as absorptive capacity, R\&D performance and technology level. Further, innovation is measured in different ways and under different names, e.g. innovation generation (Roy et al., 2004), innovation competence (Gellynck et al., 2007), innovative capability (Petroni and Panciroli, 2002), continuous

\footnotetext{
${ }^{1}$ Small and medium enterprises (SMEs) are companies that employ fewer than 250 people and have a maximum turnover of fifty million Euros.
}

innovation (Soosay et al., 2008), innovation capability (Tuominen and Hyvönen, 2003), successful innovations (Omta, 2002, Pannekoek et al., 2005) and autonomous and system innovation (Bröring, 2008). All approaches measure innovation factors internal and external to the enterprise. Internal factors relate to company characteristics, whereas external factors refer to interactions and interdependences with the enterprises environment. However, few of these studies focus in particular, but not exclusively, on the innovativeness of SMEs. Moreover, in most of these studies the unit of data collection is one focal enterprise rather than several members of a value chain or network (Tuominen and Hyvönen, 2003; Pannekoek et al., 2005; Gellynck et al., 2007; Soosay et al., 2008).

A widely applied validated scale for the measurement of innovation is currently not available. The important challenge lies in developing a measurement that is both overarching (in the sense that it grasps the different steps and domains of innovation) and explicit (in the sense that it grasps the specificity of the observed business sector). Further, it should enable the measurement of innovation at company and value chain level. Such an approach would thus be holistic and specific at the same time.

Hence, the aim of this paper is twofold: (1) to propose an approach for innovation measurement that fulfils these criteria and (2) to evaluate the suitability of this measurement to assess the value chain's innovation capacity. The approach for innovation measurement will be developed in the next section together with the conceptual framework. The proposed approach will then be evaluated by means of three surveys conducted at firm and at value chain level, described in the following sections. Finally conclusions are drawn, managerial implications provided and an outlook for future research is suggested.

\section{Development of a conceptual framework for investigating innovation capacity}

\section{Conceptual framework}

The increasing complexity of the innovation process has enhanced its dependency on interaction between different actors of the value chain and on a firm's access to external knowledge (Avermaete et al., 2004b; Edwards et al., 2005; Zeng et al., 2010). Therefore, we propose that it is necessary to not only investigate the outcome of the innovation process, but also to focus on the capacity of the firm to perform this innovation process. Our conceptual framework (Figure 1) depicts the process of innovation (driven by both internal and external resources) (Cassiman and Veugelers, 2002) leading to innovation capacity at firm and value chain level. 


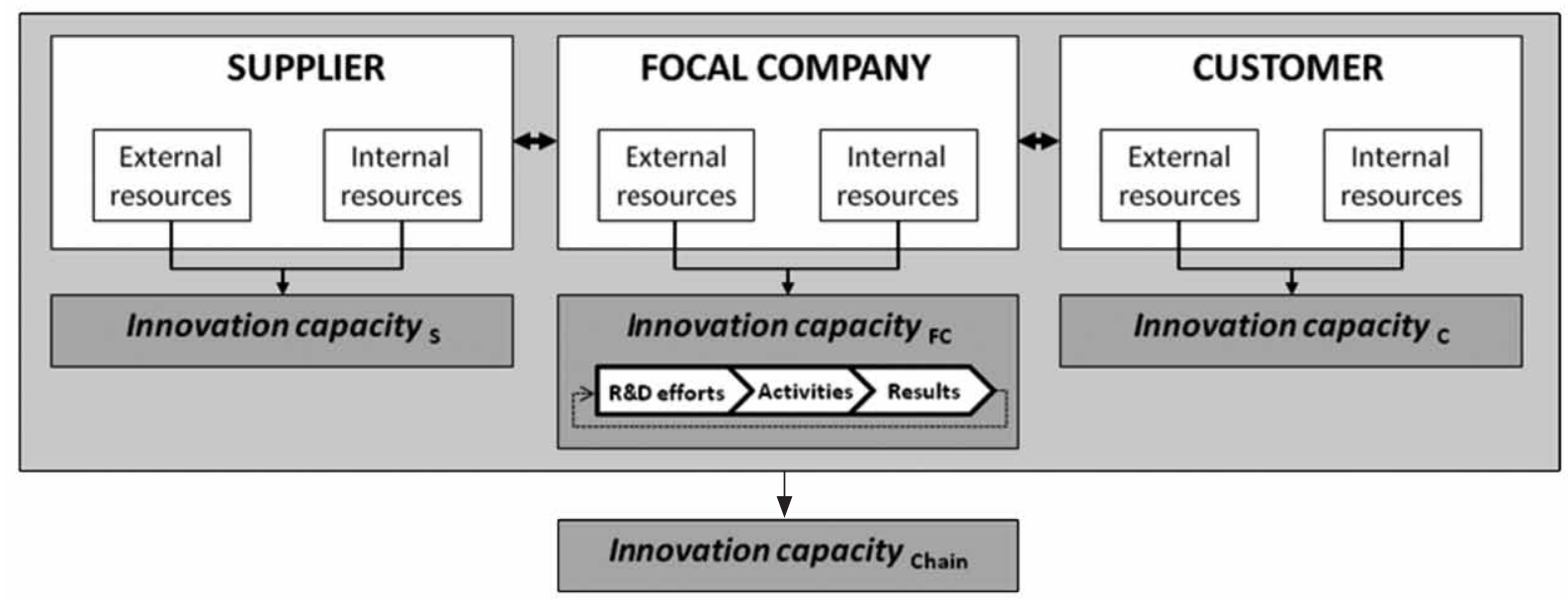

Figure 1. Conceptual framework for investigating innovation capacity at company and value chain level. S: supplier, FC: focal company, C: customer

Internal and external resources are considered complementary, because each chain partner depends on access to information to achieve enhanced levels of innovation (Avermaete et al., 2004b; Cassiman and Veugelers, 2002; Gellynck et al., 2007; Pannekoek et al., 2005; Petroni and Panciroli, 2002; Roy et al., 2004). Internal resources refer to the R\&D structure and a vast number of firm characteristics such as size, financial structure, qualified staff, experience of the manager and openness to new ideas, all of which influence innovation processes (Grünert et al., 1997; Diederen et al., 2000; Fey and Birkinshaw, 2005). External resources belong to the firm's strategic environment and include the potential of business-to-business relationships, available infrastructure for collaboration and networking, and access to support from research providers and government (Ussman et al., 1999; Avermaete and Viaene, 2002; Scozzi et al., 2005). In other words, external resources encompass the contextual elements contributing to innovation processes with regard to the inflow of knowledge from sources external to the firm (Iammarino, 2005). These sources refer to a wide range of commercial and societal actors, such as suppliers and customers of the focal company on the one hand, and research institutes, universities and governments on the other hand (Omta, 2004). Through the optimal use of both internal and external resources, a firm can become innovative and able to achieve sustainable competitive advantage (Lengnick-Hall, 1992; Cassiman and Veugelers, 2002).

In our framework, the first focus is on the capacity of the firm to perform the innovation process (i.e. its innovation capacity), which can be defined as the ability of the firm (now and in the future) to develop innovation throughout the whole innovation process (Gellynck et al., 2007). Innovation is thus understood to be a continuous process characterized by three steps, all investigated in the context of this research: efforts, activities and results. Efforts are all structured $R \& D$ resources (e.g. R\&D budget) and non-structured R\&D resources (e.g. training, study tours and small-scale experiences) a firm invests in innovation activities. Activities consist of the implementation of the necessary steps to translate the innovative knowledge and ideas into a commercial application. Activities are diverse by nature but are situated within four domains of innovation, namely product, process, organization and market. Results are the impact of these activities on tangible (e.g. growth of market share, profit) as well as less tangible aspects (e.g. firm stability, efficiency, and reputation) (Gellynck et al., 2006). This innovation process is cyclical, as the results influence future innovation capacity.

Considering the high dependency of firms on external sources of information for innovation and their need to open up their innovation process to their value chain, the second focus of our framework is on the innovation capacity of the whole value chain. In this research, we define value chain innovation capacity as a global appraisal of the innovation capacity of the focal company as well as its main suppliers and customers, with whom the focal company is closely associated. High innovation capacity of the value chain is expected to be achieved when the following conditions are fulfilled: the various actors of the value chain have a high innovation capacity and there is intensive collaboration between the focal company and its main suppliers and customers (Roy et al., 2004; Soosay et al.; 2008, Weaver, 2008). 
In the remainder of this paper, we will test and validate our approach using the example of the agrifood sector. This sector is considered to be a low-tech industry (Kirner et al., 2009), in which comparatively little innovation takes place (CIAA, 2009; Lagnevik et al., 2004). Specifically only 2\% of new products are regarded as radical (breakthrough) or equity transfer products (new to the category). The main area of product innovation in this sector comprises 'me-too' products, and these account for almost $77 \%$ of all launched products (Lagnevik et al., 2004). Another important aspect is the high failure rate of innovations, representing $72-88 \%$ (Stewart-Knox and Mitchell, 2003). The low-innovation, low-tech and high SME character of the agrifood sector and the resulting scarcity of radical innovations make it well suited as a context in which to test the framework (Lagnevik et al., 2004; Gellynck et al., 2007; CIAA, 2009; Kirner et al., 2009).

\section{Proposal of an approach to measure innovation capacity}

Innovation capacity is a latent construct with many dimensions that have not yet been clearly defined. There is also no widely applied and validated scale available to measure it.

In previous studies, innovation capacity was often measured using indicators such as the number of incremental and radical innovations a firm had introduced, the number of its patents, the budget for R\&D or the number of its employees involved in R\&D (Avermaete and Viaene, 2002; Batterink et al., 2006; Maravelakis et al., 2006; O'Regan et al., 2006; OECD, 2005; SMEs-NET, 2005). However, such indicators are less applicable to SMEs, which seldom draw on pure R\&D activities and rarely have a clearly defined R\&D budget (Avermaete et al., 2004a; Kirner et al., 2009; OECD, 2005). Furthermore, most $R \& D$ statistics categorize firms as ${ }^{\prime} R \& D$ active' if they have at least one R\&D employee. However, this indicator is, in principle, not applicable to micro- and small food manufacturers, thereby impeding the reliability of $R \& D$ statistics in the analysis of innovation (Kirner et al., 2009).

Hence, the aim of this paper is to develop a measurement instrument that encompasses the different steps and domains of innovation, but also grasps the specificity of the agrifood sector. Furthermore, we aim at developing a measurement instrument that allows the assessment of innovation capacity at both firm and value chain level. Within the relevant literature it is stressed that describing innovation using a single indicator fails to capture all of its aspects (Hertzfeld et al., 2006; Wijnands et al., 2007). Therefore, it is necessary to use several indicators to assess the inputs, processes and outputs of innovation (Carayannis and Provance, 2008; OECD, 2005).

\section{Innovation capacity at firm level}

As indicated earlier, innovation capacity refers to the ability to develop innovation throughout the whole innovation process, which consists of three steps: efforts, activities and results. All three aspects will be clarified in the next paragraphs.

Innovation efforts can be categorized as non-structured (human) and structured (financial) resources (Moris and Strubbe, 2006). Knowledge and time are closely linked to these. Assessing efforts for innovation is one of the most important aspects of innovation surveys (Carayannis and Provance, 2008). Due to the limited availability of data on innovation efforts within SMEs, the Oslo Manual recommends that the last year of the observation period be referred to as the reference year, instead of using a multiyear approach (OECD, 2005).

- Human efforts. Much knowledge is tacit in nature and embodied in people and their skills. Such skills are necessary to use external sources of knowledge efficiently (OECD, 2005). A way of measuring human efforts is through the investments firms make to improve the human capital of their employees (Moris and Strubbe, 2006; OECD, 2005). Such efforts can be training courses, seminars, study tours or experimental trials (Batterink et al., 2006; Gellynck et al., 2007; Noronha Vaz et al., 2004).

- Financial efforts. It is very difficult to calculate innovation expenditures for SMEs (Gellynck et al., 2007; Noronha Vaz et al., 2004; OECD, 2005). However, R\&D spending is considered a good measure of input to innovation (OECD, 2005). In recognition of the obstacles faced by SMEs it is recommended to not require objective budget figures from the firms, but to investigate the extent to which financial efforts are structured in the SMEs. A good example of a validated scale for the structure of financial efforts is provided by the SMEs-NET Survey (2005-2006). This scale allows a distinction to be made between firms that do not spend financial resources on innovation activities and those that do. The latter group is then further categorized into those that spend according to their current needs and those that have a defined budget per project or per year. To assess financial efforts the Oslo Manual recommends the use of a breakdown by domain, i.e. product, process, market and organizational innovation (OECD, 2005).

Innovation activities refer to the development of innovations which follow from structured and non-structured innovation efforts. As stated above, in this research the range of innovation activities includes not only new or improved products and processes, but also new or improved markets and organization (Avermaete et al., 2004a; Lundvall, 1995; OECD, 2005). This is more appropriate for the agrifood 
sector, in which changes are relatively non-technological but can still be drastic (Earle, 1997). Innovation activities are measured as innovation counts, i.e. a list of innovations implemented by the firm, as this clearly indicates the output of the innovation efforts and activities (Morck and Yeung, 2001). Furthermore, a clear definition of what constitutes an innovation, and what does not, was provided during the survey.

Innovation results. The aim of any innovation is to improve the firm's performance (Kirner et al., 2009; OECD, 2005). Based on the efforts a firm invests in its innovation process and the subsequent innovation activities, the firm will perceive benefits in terms of tangible aspects, such as profit and growth of market share, and less tangible aspects, such as firm stability and efficiency (Batterink et al., 2006; Gellynck et al., 2007). As SMEs are barely able to enumerate their R\&D budget, it is equally hard for them to estimate the impact of an innovation on their performance (Gellynck et al., 2007; Noronha Vaz et al., 2004). Consequently, in this research we chose to assess the importance of applied innovation activities to business success. This indicator refers to general evaluation by the respondent, including both the tangible and the less tangible aspects of the innovation activities (Gellynck et al., 2007).

\section{Innovation capacity at value chain level}

Aside from the three main indicators (innovation efforts, activities and results) described at firm level, a fourth indicator was included to assess the innovation capacity at the level of the value chain. This was determined by combining the innovation capacity at the firm level of all value chain partners with the indicator for collaboration for innovation among the value chain partners. To reflect the value chain's view, data from three firms belonging to the same chain were collected, whereby each chain partner was required to answer questions about his/her up- and downstream counterparts (Spekman et al., 1998). The fourth indicator is described in further detail below.

Collaboration related to innovation: System approaches draw attention to interaction between firms and between firms and their environment, demonstrating that this is an important factor for improving our understanding of innovation capacity (OECD, 2005). These interactions include the relationships between different actors, such as the chain members, peers and third parties (Batterink et al., 2006; Noronha Vaz et al., 2004; Pittaway et al., 2004). Data on the linkages in the innovation process (joint efforts, joint activities, and joint results) can be collected related to the active co-operation of firms with other enterprises and/or public research institutions in terms of innovation activities. In this research only the linkages within the value chain are considered.

Survey questions on the linkages should refer to all domains of innovation, i.e. product, process, market and organizational innovation (OECD, 2005). For such questions binary (yes/no) or ordinal scales can be used. Ordinal scales have the advantage of identifying the most important linkages, but they also limit the options for designing questions on the linkages. The advantage of the binary scale is its simplicity and reliability. However it only provides limited information on the aspects considered. In particular for complex questions, e.g. combining several aspects relating to each level of innovation, the only feasible scales are binary scales (OECD, 2005). In this research collaboration regarding innovation was assessed in a combined questionnaire probing for collaboration of the respondent with his/her supplier and customer. Hence, a binary scale was applied.

\section{Application at company level}

To verify the validity of the conceptual framework for investigating innovation capacity at company level, two surveys were conducted. The first was conducted among small food manufacturing firms exclusively and focused on product and process innovation only, while the second was conducted among food processing firms as well as their related distribution firms and main suppliers. The focus in the second study was on all four domains of innovation recognized in the conceptual framework.

The first survey measured innovation capacity in various European regions based on only two indicators: structured efforts and activities. The second survey built on the first, extending the number of indicators in order to not only measure the efforts and activities, but the whole innovation process in the firm, including the results of the firm's innovation efforts and activities.

\section{Materials and methods}

In the first survey, innovation efforts were measured based on the percentage of the firm's annual turnover spent on $\mathrm{R} \& \mathrm{D}$ activities. Innovation activities were measured based on whether the firm introduced substantially modified products or processes over the previous five years. This survey was conducted among small food manufacturing firms (with between 3 and 50 employees) in six European regions. Bakeries were excluded from the sample to avoid the inclusion of small retail shops. Based on information from national institutes of statistics, regional and local authorities and commercial bodies, 691 firms were identified that fulfilled the conditions of the research. Quota sampling was 
used to select 30 firms in each of the six regions. Eventually 177 small food firms participated, representing more than one-fourth of the target population. A pilot was carried out in May 2001 and the complete survey was conducted from July to December 2001 by means of in-depth, face-to-face interviews lasting 1-1 $1 \frac{2}{2}$ hours with the top manager or owner of each firm. Data were analyzed using hierarchical and k-means cluster analysis on the four variables.

Building on the results of the first survey, the second survey used four variables to measure each firm's innovation capacity: budget in $\mathrm{R} \& \mathrm{D}$, man-hours in implicit knowledge acquisition, number of domains of innovation involved and importance of innovations. The first two variables measured the first step in building innovation capacity, namely the efforts. First, R\&D investments were assessed by identifying the extent to which an R\&D budget was applied in a structured way to different innovation domains. Even though structured R\&D investments are widely used by researchers as an indicator of the firm's innovation capacity and have been proven useful in the food manufacturing survey, the firm's innovation capacity was also measured based on non-structured innovation efforts. This relates to the firm's implicit methods of knowledge acquisition, such as education and training, self-study, participation in seminars, field work and small-scale experiments, as research demonstrates that, particularly in the case of SMEs, only a minority of firms structurally invests in R\&D (Avermaete et al., 2004a). The third variable measured the second step of building innovation capacity, the innovation activities. They were considered intensive if performed in all four domains of innovation. Finally, the fourth variable measured the last step of building innovation capacity, the results. Respondents were asked to evaluate the importance of innovations to business success, including both tangible (e.g. growth of market share, profit) and less tangible aspects (e.g. firm stability, efficiency) .

The second survey thus differed from the first in three ways: the role of implicit or non-structured R\&D efforts was acknowledged; the scope was broadened to include market and organizational innovation; and results were measured in addition to efforts and activities.

In the second survey primary data were collected using a structured questionnaire that measured the innovation capacity of the firm and its relation to the four regional characteristics described in the conceptual framework: the regional networks, the regional food chain, market and the regional facilities. Data were gathered at three levels of the agri-business complex: (1) food processing firms, (2) trade firms (wholesale trade) and (3) main suppliers (excluding farmers). A sample of 81 firms, which is $50 \%$ of the total target population of the Meetjesland region (163 firms), was surveyed by means of face-to-face interviews performed in March and April 2005. Data were analysed using hierarchical and k-means cluster analysis on the four variables.

Table 1 summarizes the materials and methods used for each of these surveys. For further details on materials and

Table 1. Food manufacturing and food firms surveys: materials and methods.

\section{Survey}

Food manufacturing survey

(Avermaete et al., 2004a)

Survey location

Devon and Cornwall region, United Kingdom

\begin{tabular}{lll} 
& Hereford and Worcester region, United Kingdom \\
& Hainault region, Belgium \\
& West Flanders region, Belgium \\
& Northwest Border region, Ireland \\
& South West region, Ireland & \\
\hline Survey period & July to December 2001 & March and April 2005 \\
\hline Target population & Small food manufacturing firms & Food processing firms
\end{tabular}

\begin{tabular}{lll} 
& Hereford and Worcester region, United Kingdom \\
& Hainault region, Belgium \\
& West Flanders region, Belgium \\
& Northwest Border region, Ireland \\
& South West region, Ireland & \\
\hline Survey period & July to December 2001 & March and April 2005 \\
\hline Target population & Small food manufacturing firms & Food processing firms
\end{tabular}

\begin{tabular}{lll} 
& Hereford and Worcester region, United Kingdom \\
& Hainault region, Belgium \\
& West Flanders region, Belgium \\
& Northwest Border region, Ireland \\
& South West region, Ireland & \\
\hline Survey period & July to December 2001 & March and April 2005 \\
\hline Target population & Small food manufacturing firms & Food processing firms
\end{tabular}

\begin{tabular}{lll} 
& Hereford and Worcester region, United Kingdom \\
& Hainault region, Belgium \\
& West Flanders region, Belgium \\
& Northwest Border region, Ireland \\
& South West region, Ireland & \\
\hline Survey period & July to December 2001 & March and April 2005 \\
\hline Target population & Small food manufacturing firms & Food processing firms
\end{tabular}

\begin{tabular}{lll} 
& Hereford and Worcester region, United Kingdom \\
& Hainault region, Belgium \\
& West Flanders region, Belgium \\
& Northwest Border region, Ireland \\
& South West region, Ireland & \\
\hline Survey period & July to December 2001 & March and April 2005 \\
\hline Target population & Small food manufacturing firms & Food processing firms
\end{tabular}

\begin{tabular}{lll}
\hline Survey period & July to December 2001 & March and April 2005 \\
\hline Target population & Small food manufacturing firms & $\begin{array}{l}\text { Food processing firms } \\
\text { Trade firms (wholesale trade) } \\
\end{array}$ \\
& & Main suppliers (excluding farmers) \\
\hline Number of firms surveyed & 177 & 81 \\
\hline Data collection & Structured face-to-face interviews & Structured face-to-face interviews \\
\hline Domains & Product and process innovation & $\begin{array}{l}\text { Product, process, organizational and market } \\
\text { innovation }\end{array}$ \\
& &
\end{tabular}

Agrifood businesses' survey

(Gellynck et al., 2007)

Meetjesland region, Belgium 
methods the reader is referred to Avermaete et al. (2004a) and Gellynck et al. (2007).

\section{Key findings}

The food manufacturing survey revealed four distinct innovation groups: non-innovators, traditionalists, followers and leaders, depending on whether they had achieved any innovation in the past and their investment in R\&D (Table 2). Non-innovators were firms that had not introduced new or substantially modified products or processes during the previous five years. Traditionalists were firms that had introduced product or process innovations, but had not invested in R\&D. Followers and leaders were firms that had introduced product or process innovations and who had invested in R\&D activities, respectively. Followers had spent at most $1 \%$ of their annual turnover on $R \& D$, whereas leaders' expenditures had exceeded this level.
Most of the firms were followers (44.1\%), followed by the traditionalists (21.5\%) and leaders (18.1\%). Of the 148 innovating firms, the majority (100 firms) had introduced both product and process innovations (Avermaete et al., 2004a). A small minority (10 firms) had introduced only process innovations, while another 38 firms had introduced only product innovations. The co-incidence of product and process innovation was verified by cross-tabulation using Chi square statistics $\left(\chi^{2}=28,338, P=0.000\right)$.

Interestingly, the results indicated that the traditional firms, which had not invested in $\mathrm{R} \& \mathrm{D}$, still introduced at least one innovation in the previous five years. These included, for example, a regional food label within the framework of the regional LEADER programme, which supports innovation projects undertaken by local action groups. This suggests that investment in R\&D alone does not explain a firm's innovation capacity. Networking with other firms or organizations such as public institutions may also be a decisive factor.

Table 2. Innovation groups of food manufacturing survey, $\mathrm{n}=177$.

\begin{tabular}{lcccc}
\hline & Non-innovators & Traditionalists & Followers & Leaders \\
& & 38 & 78 & 32 \\
Number of firms & 29 & 21.5 & 44.1 & 18.1 \\
Percentage of firms & 16.4 & 0 & 0.50 & 6.53 \\
R\&D expenditures as \% of turnover & No & Yes & Yes & Yes \\
Introduction of at least one innovation type of (product/ & & &
\end{tabular}

Table 3. Innovation gropus of Agrifood businesses' survey, $n=76^{a}$.

\begin{tabular}{|c|c|c|c|c|}
\hline & \multicolumn{4}{|l|}{ Clusters } \\
\hline Variable & Non-innovators & Followers & Innovators & Significance ${ }^{b}$ \\
\hline Number of firms & 31 & 33 & 12 & \\
\hline Percentage of firms & 40.8 & 43.4 & 15.8 & \\
\hline \multicolumn{5}{|l|}{ Mean differences in one-way ANOVA } \\
\hline Budget in R\&D & $-0.3^{c}$ & $-0.2^{\mathrm{C}}$ & $0.3^{d}$ & 0.007 \\
\hline Man-hours in implicit knowledge-acquisition & -0.3 & 0.0 & -0.3 & 0.073 \\
\hline Number of domains of innovation & $-1.0^{c}$ & $0.5^{d}$ & $1.2^{\mathrm{e}}$ & 0.000 \\
\hline Importance of the innovation & $-1.0^{c}$ & $0.5^{d}$ & $1.8^{\mathrm{e}}$ & 0.000 \\
\hline
\end{tabular}

a Five outliers were removed from the analysis.

b Significance $P<0.05$ (One-way ANOVA).

Procedure: Hierarchical Cluster Analysis (Ward's method) \& subsequent K-means method.

Distance Measure: Euclidean Squared Distance.

Mean scores are standardized scores (Z-scores).

$c, d, e$ Letters in superscripts indicates different subsets in Duncan's test, referring to significant differences between group means. 
In the agribusiness survey, three statistically significant clusters were identified: non-innovators, followers and innovators (Table 3). Non-innovators had the lowest cluster means in all aspects compared to the other two clusters. The second cluster contains firms that had very low scores in spending a budget on $R \& D$, but were relatively active in the four domains of innovation and also achieved a positive score with respect to importance of their innovation outcomes. Due to their underspending on $\mathrm{R} \& \mathrm{D}$, but positive innovation activities and results, the second cluster was named followers, as they might primarily copy the innovation activities from the firms in the third cluster, without investing an R\&D budget in development of their own innovations. Finally, the third cluster is composed of firms with significantly higher scores on three out of the four indicators compared to the other two clusters. Hence, these firms were labelled innovators.

The distribution in the different clusters is similar to that in the food manufacturing survey. Followers form the largest group (43.4\%). Innovators, which are equivalent to the leaders cluster in the first survey, account for less than $20 \%$ of the total population. However, the relative share of the non-innovators is only slightly lower than the followers. Observing the cluster centres, the differences between the clusters are explained primarily by three out of the four variables: budget in $R \& D$, number of domains of innovation involved and importance of innovation. No significant difference exists between the clusters regarding implicit knowledge acquisition. This could confirm the view that structured R\&D efforts (i.e. R\&D investments) are the most reliably proxy for innovation efforts. Alternatively, it may not be the number of man-hours in non-structured $R \& D$ that makes the difference, but the quality and strategic use of non-structured R\&D efforts. Clarification of this point would require further investigation.

\section{Evaluation}

Comparing the two surveys reveals that using indicators for innovation efforts, activities and results at firm level is a good way to assess the firms' innovation capacity and categorize them in various groups.

Innovation efforts. The results of both surveys show that the assessment of $\mathrm{R} \& \mathrm{D}$ expenditures contributed to recognizing clear distinctions between the firms and dividing them into different categories of innovation capacity. In accordance with the noted limitations of SMEs in reporting objective data (see section 2.2), the R\&D expenditures were assessed as percent of turnover (food manufacturing survey) and whether the budget for innovation was structured according to different innovation domains (agrifood businesses' survey). In both surveys a positive relationship between
R\&D expenditures and higher levels of innovation capacity was found. Remarkably, the non-structured R\&D efforts did not differ among the clusters. This might indicate that firms that do not have an explicit R\&D budget are constantly concerned with innovation in any form.

Innovation activities. It became clear from the first survey that product and process innovation are clearly interlinked. However, the second survey revealed that innovating firms are active in all four domains of innovation: they not only implement product and process innovation but also market and organizational innovation. Broadening the approach to all four domains of innovation thus provides a clearer picture of innovation activities at firm level.

Innovation results. These were only assessed in the second survey. The data showed that the importance of the innovation to business success increases with increased levels of the other three indicators. As defined, the innovation process is cyclical and good innovation results will positively influence the innovation capacity in the future. Hence, this is also an important indicator for assessing innovation capacity, contributing to a more complete picture of the whole innovation process.

\section{Application at value chain level}

To test the conceptual framework at value chain level, a third survey was conducted in the agrifood sector, which considered the perspectives of three value chain members belonging to the same chain. The focus was on all four domains of innovation. To broaden the level of data analysis to the value chain level, an additional variable was introduced covering the aspect of collaboration for innovation between the three value chain members, i.e. supplier, focal company and customer.

\section{Materials and methods}

For the investigation of the innovation capacity in value chains, the indicators for innovation efforts, activities and results of the individual chain members, and an indicator for collaboration of innovation between the value chain members were used. Innovation efforts included structured and non-structured efforts. Structured effort was defined as whether the value chain members had distinctive budgets for the different innovation domains. Non-structured efforts related to the frequency of implicit knowledge acquisition by the person responsible for $R \& D$ in the firm. Innovation activities were assessed in different subdomains of three out of the four main domains, i.e. product, market and organizational innovation. This survey was conducted in the traditional food sector (e.g. Parma ham), in which process innovations seldom occur, so these were not included in 
our model (Gellynck and Kühne, 2008). Innovation results were measured by the respondent's general evaluation of the importance of innovations to his/her business success, comprising both tangible (e.g. growth of market share, profit) and less tangible aspects (e.g. firm stability, efficiency). Finally, to assess collaboration for innovation among the chain members, the food manufacturer was asked whether he/she was collaborating for innovation with his/her supplier and customer, while the supplier and customer were asked the same question related to their collaboration with their food manufacturer.

The survey was conducted in 90 value chains (triplets of 270 associated value chain members) in three European countries and six different food sectors (see Table 4). A structured questionnaire was used in face-to-face interviews with all 270 value chain members. During the interviews, a snowball sampling technique was applied in order to receive the contact details of the food manufacturer's main supplier and customer. This assured that for each of the 90 value chains, three chain members were identified that were interlinked with each other. Data were analysed using hierarchical and k-medoid cluster analysis on the five variables. Materials and methods are summarized in Table 4.

\section{Key findings}

In the value chain survey, three significantly different clusters of innovative capacity could be identified: low, medium and high (Table 5). In the first cluster, we interpreted the results as indicating that these chain members all have very low innovation capacity compared to the other clusters. Very little collaboration for innovation between these chain members was evident. Hence, we labelled this cluster 'Chains with low innovation capacity'. In the second cluster, all chain members indicated a higher level of innovation capacity than the members in the first cluster, but they were not reaching the level of innovation capacity of the chain members in the third cluster. However, the suppliers and food manufacturers were indicating higher levels than the customers, which might be due to the fact that customers in these chains are micro-sized ( $<10$ employees) (Gellynck et $a l, 2010)$. Furthermore, there is also not much collaboration for innovation capacity. This cluster was labelled 'Chains with medium innovation capacity'. Finally, the third cluster comprises chains in which all chain members indicated higher innovation capacity compared to those in the other clusters and there was intense collaboration for innovation between all chain members. Consequently, this cluster was named 'Chains with high innovation capacity'. These results also indicate that the more interaction that exists between all chain members, the higher the innovation capacity of each single member of the value chain will be.

More than half of the participating chains were categorized as Chains with medium innovation capacity $(54.4 \%)$. There was also a large share of Chains with low innovation capacity $(>30 \%)$. Chains with high innovation capacity accounted for the smallest share of the sample. This distribution was not surprising, considering the nature of the traditional food products sector, but also because it followed the trend of the two surveys at firm level.

The differences between the three clusters are explained by all indicators. Only 3 out of 16 indicators showed no significant differences, i.e. for the customers regarding the non-structured efforts and for the food manufacturers and customers regarding innovation results. Hence, all indicators seem to be reliable proxies for measuring innovation capacity at chain level as well.

\section{Evaluation}

The value chain survey investigated how interaction within the value chain contributes to the innovation capacity of

Table 4. Food chain survey: materials and methods.

Food chain survey (Gellynck et al., 2010)

Survey location

Belgium (cheese and beer)

Italy (cheese and ham)

Hungary (white pepper, dry sausage and bakery products)

Survey period

December 2007 to June 2008

Target population

SMEs manufacturing traditional food products and their respective most important suppliers and customers

Number of chains surveyed

90

Data collection

Structured face-to-face interviews

Domains

Product, organizational and market innovation 
Table 5. Innovation capacity of value chains, k-medoid cluster analysis, $n=90$.

\begin{tabular}{|c|c|c|c|c|}
\hline \multirow[b]{2}{*}{ Innovation capacity } & \multicolumn{4}{|l|}{ Cluster } \\
\hline & $\begin{array}{l}\text { 1. Chains with low } \\
\text { innovation capacity } \\
n=31(34.4 \%) \\
\text { Cluster centre }^{8}\end{array}$ & $\begin{array}{l}\text { 2. Chains with medium } \\
\text { innovation capacity } \\
\mathrm{n}=49(54.4 \%) \\
\text { Cluster centre }\end{array}$ & $\begin{array}{l}\text { 3. Chains with high } \\
\text { innovation capacity } \\
n=10(11.1 \%) \\
\text { Cluster centre }^{8}\end{array}$ & K-W Sig. ${ }^{7}$ \\
\hline \multicolumn{5}{|l|}{ Non-structured R\&D efforts ${ }^{1}$} \\
\hline Food manufacturer (FM) & $0.00^{\mathrm{a}}$ & $0.33^{b}$ & $0.50^{c}$ & 0.002 \\
\hline Supplier $(S)$ & $0.00^{\mathrm{a}}$ & $0.33^{b}$ & $0.63^{c}$ & 0.000 \\
\hline Customer (C) & 0.00 & 0.17 & 0.33 & 0.069 \\
\hline \multicolumn{5}{|l|}{ Structured innovation efforts ${ }^{2}$} \\
\hline Food manufacturer & $0.00^{\mathrm{a}}$ & $0.33^{b}$ & $0.33^{b}$ & 0.000 \\
\hline Supplier & $0.00^{\mathrm{a}}$ & $0.33^{b}$ & $0.17^{b}$ & 0.000 \\
\hline Customer & $0.00^{\mathrm{a}}$ & $0.00^{\mathrm{a}}$ & $0.50^{\mathrm{b}}$ & 0.000 \\
\hline \multicolumn{5}{|l|}{ Innovation activities ${ }^{3}$} \\
\hline Food manufacturer & $0.33^{\mathrm{a}}$ & $0.56^{\mathrm{b}}$ & $0.72^{c}$ & 0.001 \\
\hline Supplier & $0.22^{\mathrm{a}}$ & $0.44^{b}$ & $0.44^{b}$ & 0.000 \\
\hline Customer & $0.33^{\mathrm{a}}$ & $0.44^{\mathrm{a}}$ & $0.76^{b}$ & 0.002 \\
\hline \multicolumn{5}{|l|}{ Innovation results ${ }^{4}$} \\
\hline Food manufacturer & 0.67 & 0.75 & 0.83 & 0.094 \\
\hline Supplier & $0.67^{\mathrm{a}}$ & $0.75^{\mathrm{b}}$ & $0.67^{\mathrm{b}}$ & 0.000 \\
\hline Customer & 0.67 & 0.75 & 0.67 & 0.215 \\
\hline \multicolumn{5}{|l|}{ Collaboration for innovation 5} \\
\hline$F M-S^{6}$ & $0.00^{\mathrm{a}}$ & $0.00^{\mathrm{a}}$ & $1.00^{\mathrm{b}}$ & 0.000 \\
\hline $\mathrm{FM}-\mathrm{C}^{6}$ & $0.00^{\mathrm{a}}$ & $0.00^{\mathrm{a}}$ & $1.00^{\mathrm{b}}$ & 0.001 \\
\hline S-FM ${ }^{6}$ & $0.00^{\mathrm{a}}$ & $0.00^{\mathrm{a}}$ & $1.00^{\mathrm{b}}$ & 0.000 \\
\hline C-FM ${ }^{6}$ & $0.00^{\mathrm{a}}$ & $0.00^{\mathrm{a}}$ & $1.00^{\mathrm{b}}$ & 0.002 \\
\hline
\end{tabular}

a,b Various superscripts indicate significant differences of group medians in the Mann-Whitney U post hoc test $(P<0.05)$.

${ }^{1}$ Measured on a 7-point frequency scale, with 1 (never applying human innovation efforts) to 7 (Applying human innovation efforts several times a week).

${ }^{2}$ Measured on a 4-point scale, with 1 (never spending financial resources for innovation efforts) to 4 (having a distinct budget on year-base for innovation efforts).

${ }^{3}$ Measured on a Yes-No-Non applicable scale for introduction of innovation activities, presenting the relative score of applicable innovation activities on a range from 0 (no innovation activities are applied) to 1 (all applicable innovation activities are applied).

${ }^{4}$ Measured on a 7-point Likert scale indicating the extent of agreement that the applied innovation activities (see ${ }^{3}$ ) contributed to success of the company, with 1 (strongly disagree) to 7 (strongly agree).

${ }^{5}$ Measured on a binary scale with 0 (no collaboration for innovation) and 1 (collaboration for innovation).

${ }^{6}$ Indicates the collaboration for innovation between two value chain members, whereby the first mentioned is answering whether he/she collaborates with the second mentioned, e.g. 'FM-S' refers to the answers of the food manufacturer towards his/her supplier.

${ }^{7}$ Reports estimated significances of the Kruskal-Wallis test, significance $P<0.05$.

${ }^{8}$ Median scores represent standardized scores in a closed interval $[0,1]$.

SMEs. The results show that this is a good proxy for assessing innovation capacity at value chain level. With this survey the measurement of innovation capacity was extended to the level of personalized, individual chains, thereby contributing to a better understanding of how innovation capacity is achieved in value chains. We were able to show that higher 
innovation capacity and collaboration for innovation appear simultaneously, though few chains in the agrifood sector have attained this level yet. In further research it would be interesting to investigate the contribution of one value chain member's innovation capacity to the innovation capacity of the other value chain members.

\section{Conclusion}

This study presented an approach for measuring innovation capacity, acknowledging the specific and holistic character of innovation and applying it to SMEs in the agrifood sector. Further, based upon earlier research findings drawing attention to the importance of collaboration in chains and networks for developing innovation capacity, the approach was extended to measure innovation capacity at value chain level.

Indeed, the analysis showed that extending the concept of innovation capacity from company to the value chain level delivers valuable results. The finding that value chains differ with respect to their overall innovation capacity reveals that SMEs will perform better when they belong to value chains with intense collaboration between value chain partners in order to become more innovative themselves. Collaboration is important to gain access to external sources of innovation, as value chain members and other partners of the direct environment are the main sources for innovative ideas (Pannekoek et al., 2005; Gellynck et al., 2007).

Furthermore, the results of all three surveys show that SMEs that focus only on their innovation activities (i.e. the translation of the innovative knowledge and ideas into a commercial application) without acknowledging the importance of structured and non-structured efforts as necessary inputs for these activities will have lower innovation results. Although the majority of all firms investigated in the three surveys belong to this category ('Traditionalists', 'Followers' and 'Chains with medium innovation capacity'), there are few good examples, showing that investment in structured and non-structured efforts is paying off in terms of more innovation activities and better innovation results, which in return are probably positively influencing the investment in innovation efforts.

The conceptual framework and the presented empirical inquiries have resulted in an applicable and empirically tested scale for measuring innovation capacity. The observations proved to be reliable across the different datasets and the inclusion of descriptive variables in the different studies underpins its validity (Avermaete et al., 2003). Furthermore, the scale was tested in different national contexts, different agrifood sectors and different types of firms (i.e. food processors, food manufacturers, farmers, distributors, etc.), which allows us to conclude that the used indicators are widely applicable. The indicators were chosen in order to address limitations faced by SMEs. Nevertheless, they might also be applicable to larger firms or multinationals. Other researchers are encouraged to apply our measurement tool for innovation capacity to other, e.g. more technology-oriented sectors, such as the pharmaceutical or biotechnology sector, that have different characteristics than the agrifood sector.

These findings were drawn from self-reported data on innovation capacity, which has some essential limitations. Self-reported perceptions are not always trustworthy, as psychological and social processes influence the storage and recall of self-report information (Stone et al., 2000; Gellynck et al., 2006; Gellynck et al., 2007). Further, social desirability and the level of knowledge and experience of the respondent may invoke a bias (Lee et al., 2000). Future research attempts should include a scale in the survey which measures the respondent's knowledge level and the effect of social desirability.

In future research it would also be interesting to explore how the benefits of increased innovation capacity are divided between the value chain members and how the level of innovation capacity of each value chain member contributes to the innovation capacity of the others.

\section{References}

Antonelli, C., 2006. Diffusion as a Process of Creative Adoption. Journal of Technology Transfer, 31: 211-226.

Avermaete, T. and J. Viaene, 2002. On Innovation and Meeting Regulation - the Case of the Belgian Food Industry. DRUID Summer Conference on 'Industrial Dynamics of the New and Old Economy - who is embracing whom?' Copenhagen/Elsinore, Denmark, 6-8 June 2002.

Avermaete, T., J. Viaene, E. Morgan and N. Crawford, 2003. Determinants of innovation in small food firms. European Journal of Innovation Management, 6: 8-17.

Avermaete, T., J. Viaene, E.J. Morgan and N. Crawford, 2004a. The impact of firm characteristics and macroeconomic performance on innovation in small food firms: case study from Belgium, Ireland and UK. In: T. de Noronha Vaz, J. Viaene and M. Wigier (eds.) Innovation in Small Firms and Dynamics of Local Development. Scholar Publishing House, Warsaw, Poland, pp. 79-95.

Avermaete, T., J. Viaene, E.J. Morgan, E. Pitts, N. Crawford and D. Mahon, 2004b. Determinants of product and process innovation in small food manufacturing firms. Trends in Food Science \& Technology, 15: 474-483.

Balconi, M., S. Brusoni and L. Orsenigo, 2008. In Defence of the Linear Model: An Essay. WP n. 216. Milan, Italy, CESPRI 35. 
Batterink, M.H., E.F.M. Wubben and S.W.F. Omta, 2006. Factors related to innovative output in the Dutch agrifood industry. Journal on Chain and Network Science, 6: 31-44.

Becheikh, N., R. Landry and N. Amara, 2006. Lessons from innovation empirical studies in the manufacturing sector: A systematic review of the literature from 1993-2003. Technovation, 26: 644-664.

Bröring, S., 2008. How systemic innovations require alterations along the entire supply chain: The case of animal-derived functional foods. Journal on Chain and Network Science, 8: 107-120.

Carayannis, E.G. and M. Provance, 2008. Measuring firm innovativeness: towards a composite innovation index built on firms innovative posture, propensity and performance attributes. International Journal of Innovation and Regional Development, 1: 90-107.

Cassiman, B. and R. Veugelers, 2002. Complementarity in the innovation strategy: internal $R \& D$, external technology acquisition, and co-operation in R\&D, CEOP, pp. 1-32.

CIAA, 2009. Data \& Trends of the European Food and Drink Industry. Confederation of the food and drink industries of the EU (CIAA). Brussels, Belgium.

Dawid, H., M. Reiman and B. Bullnheimer, 2001. To innovate or not to innovate? IEEE Transactions on Evolutionary Computations, 5: 471-481.

Dewar, R.D. and J.E. Dutton, 1986. The Adoption of Radical and Incremental Innovations: An Empirical Analysis. Management Science, 32: 1422-1433.

Diederen, P., H. Van Meijl and A. Wolters, 2000. Eureka! Innovatieprocessen en innovatiebeleid in de land- en tuinbouw. Den Haag, LEI 89.

Earle, M.D., 1997. Innovation in the food industry. Trends in Food Science \& Technology, 8: 166-175.

Edwards, T., R. Delbridge and M. Munday, 2005. Understanding innovation in small and medium-sized enterprises: a process manifest. Technovation, 25: 1119-1127.

Enzing, C.M., F.H.A. Janszen and S.W.F. Omta, 2008. The impact of the openness of the innovation process on the short term and the long term market performance of new products: Evidence from new product announcements of the Dutch food and drinks industry. 8th International Conference on Management in AgriFood Chains and Networks, Wageningen Academic Publishers, Wageningen, The Netherlands, 28-30 May 2008.

Fey, C.F. and J. Birkinshaw, 2005. External Sources of Knowledge, Governance Mode, and R\&D Performance. Journal of Management, 31: 597-621.

Fischer, M.M., 2001. Innovation, knowledge creation and systems of innovation. Annals of Regional Science, 35: 199-216.

Gellynck, X., B. Kühne and R.D. Weaver, 2011. Innovation capacity of food chains: A novel approach. International Journal of Innovation and Regional Development, 3: in press.
Gellynck, X. and B. Kühne, 2008. Innovation and collaboration in traditional food chain networks. Journal on Chain and Network Science, 8: 121-129.

Gellynck, X., B. Kühne and R.D. Weaver, 2010. Relationship quality and innovation capacity of chains: The case of the traditional food sector in the EU. 4th International European Forum on System Dynamics and Innovation in Food Networks InnsbruckIgls, Austria, February 08-12, 2010.

Gellynck, X., B. Vermeire and J. Viaene, 2006. Innovation in the Food Sector: Regional Networks and Internationalisation. Journal on Chain and Network Science, 6: 21-30.

Gellynck, X., B. Vermeire and J. Viaene, 2007. Innovation in food firms: Contribution of regional networks within the international business context. Entrepreneurship and Regional Development, 19: 209-226.

Grünert, K., H. Harmsen, M. Meulenberg, E. Kuiper, T. Ottowitz, F. Declerck, B. Traill and G. Göransson, 1997. A framework for analysing innovation in the food sector. In: B. Traill and K.G. Grunert (eds.) Product and process innovation in the food sector. Chapman \& Hall, Suffolk, UK, pp. 1-33.

Grunert, K.G., B.B. Jensen, A.-M. Sonne, K. Brunsø, D.V. Byrne, C. Clausen, A. Friis, L. Holm, G. Hyldig, N.H. Kristensen, C. Lettl and J. Scholderer, 2008. User-oriented innovation in the food sector: relevant streams of research and an agenda for future work. Trends Food Science and Technology, 19: 590-602.

Hertzfeld, H.R., A.N. Link and N.S. Vonortas, 2006. Intellectual property protection mechanisms in research partnerships. Research Policy, 35: 825-838.

Iammarino, S., 2005. An evolutionary integrated view of regional systsm of innovation: Concepts, measures and historical perspectives. European Planning Studies, 13: 497-519.

Kirner, E., S. Kinkel and A. Jaeger, 2009. Innovation paths and the innovation performance of low-technology firms - An empirical analysis of German industry. Research Policy, 38: 447-458.

Lagnevik, M., I. Sjöholm, A. Lareke and J. Östberg, 2004. The Dynamics of Innovation Clusters. Edward Elgar Publishing Limited, Cheltenham Glos UK.

Lee, E., M. Hu and R. Toh, 2000. Are Consumer Survey Results Distorted? Systematic Impact of Behavioral Frequency and Duration on Survey Response Errors. Journal of Marketing Research, 37: 125-133.

Lengnick-Hall, C.A., 1992. Innovation and Competitive Advantage: What we know and what we need to learn. Journal of Management, 18: 399-429.

Lettl, C., C. Herstatt and H.G. Gemünden, 2006. Learning form users for radical innovaiton. International Journal of Technological Management, 33: 25-45.

Lundvall, B.-A., 1995. National Systems of Innovation: Towards a Theory of Innovation and Interactive Learning. London, UK, Pinter Publishers. 
Maravelakis, E., N. Bilalis, A. Antoniadis, K.A. Jones and V. Moustakis, 2006. Measuring and benchmarking the innovativeness of SMEs: A three-dimensional fuzzy logic approach. Production Planning and Control, 17: 283-292.

Mentzer, J.T., W. DeWitt, J.S. Keebler, S. Min, N.W. Nix, C.D. Smith and Z.G. Zacharia, 2001. Defining supply chain management. Journal of Business Logistics, 22: 1-25.

Miller, D.A., 2008. Invention under uncertainty and the threat of ex post entry. European Economic Review, 52: 387-412.

Morck, R. and B. Yeung 2001. The Economic Determinants of Innovation. Occasional Paper Number 25. Industry Canada Research Publication Program, pp. 89.

Moris, C. and K. Strubbe, 2006. SMEsNET Regional Assessment Report. SMEs Networking European Food Quality and Safety Stakeholders, Sixth Research and Technological Development Framework Programme. Federatie Voedingsindustrie vzw. Brussels, Belgium. January 2006. 1-11.

Noronha Vaz, T.d., J. Viaene and M. Wigier, 2004. Innovation in Small Firms and Dynamics of Local Development. Warsaw, Poland, Scholar Publishing House.

OECD, 2005. Oslo Manual - Guidelines for collecting and interpreting innovation data, OECD/European Communities.

Omta, O., 2004. Management of Innovation in Chains and Networks. In: T. Camps, P. Diederen, G.J. Hofstede and B. Vos (eds.) The Emerging World of Chains and Networks. Bridging theory and practice. Reed Business Information, 's-Gravenhage, the Netherlands.

Omta, S.W.F., 2002. Innovation in chains and networks. Journal on Chain and Network Science, 2: 73-80.

O'Regan, N., A. Ghobadian and M. Sims, 2006. Fast tracking innovation in manufacturing SMEs. Technovation, 26: 251-261.

Pannekoek, L., O. Van Kooten, R. Kemp and S.W.F. Omta, 2005. Entrepreneurial innovation in chains and networks in Dutch greenhouse horticulture. Journal on Chain and Network Science, 5: 39-50.

Petroni, A. and B. Panciroli, 2002. Innovation as a determinant of suppliers' roles and performances: An empirical study in the food machinery industry. European Journal of Purchasing \& Supply Management, 8: 135-149.

Pittaway, L., M. Robertson, K. Munir, D. Denyer and A. Neely, 2004. Networking and innovation: a systematic review of the evidence. International Journal of Management Review, 5-6: 137-168.

Powell, W.W., K.W. Koput and L. Smith-Doerr, 1996. Interorganizational Collaboration and the Locus of Innovation: Networks of Learning in Biotechnology. Administrative Science Quarterly, 41: 116-145.

Rothwell, R., 1992. Successful industrial innovation: critical success factors for the 1990's. R\&D Management, 22: 221-239.

Roy, S., K. Sivakumar and I.F. Wilkinson, 2004. Innovation Generation in Supply Chain Relationships: A Conceptual Model and Research Propositions. Journal of the Academy of Marketing Science, 32: 61-79.
Sarkar, S. and A.I.A. Costa, 2008. Dynamics of open innovation in the food industry. Trends Food Scientific Technology, 19: 574580 .

Scozzi, B., C. Garavelli and K. Crowston, 2005. Methods for modeling and supporting innovation processes in SMEs. European Journal Innovation Management, 8: 120-137.

SMEs-NET, 2005. Vision Paper - Ten Theses on Food and Drink SMEs and Innovation in Europe: Evidence on needs and policy recommendations. SMEs-NET project EC FP6 Programme, pp. $1-40$.

SMEs-NET Survey, 2005-2006. WP3 Common Assessment Questionnaire. EC FP6 Programme. http://freeonlinesurveys. com/rendersurvey.asp, 28/08/2007.

Soosay, C.A., P.W. Hyland and M. Ferrer, 2008. Supply chain collaboration: Capabilities for continuous innovation. Supply Chain Management, 13: 160-169.

Spekman, R.E., J.W. Kamauff Jr. and N. Myhr, 1998. An empirical investigation into supply chain management: A perspective on partnerships. International Journal of Physical Distribution and Logistic Management, 28: 630-650.

Stewart-Knox, B. and P. Mitchell, 2003. What separates the winners from the losers in new food product development? Trends in Food Science and Technology, 14: 58-64.

Stone, A., C. Bachrach, J. Jobe and H. Kurtzman, 2000. The science of self-report: Implications for Research and Practice New Jersey London, UK, Lawrence Erlbaum Associates, 380 pp.

Tidd, J., J. Bessant and K. Pavitt, 2005. Managing innovation. West sussex, UK, John Wiley \& Sons, Ltd.

Tuominen, M. and S. Hyvönen, 2003. Organizational Innovation Capability: Creating and Appropriating Value in Channel Relationships. 19th Industrial Marketing and Purchasing Group Conference, Lugano, Switzerland, 2003.

Ussman, A., M. Franco, L. Mendes and A. Almeida, 1999. Are SMEs Really Innovative? A Study Regarding the Main Difficulties in Portuguese SMEs. Conference Paper No. 78, Conference of the International Council for Small Business (ICSB), Small Business Advancement National Center, Naples, Italy.

Van der Vorst, J.G.A.J., 2000. Effective food supply chains: generating, modelling and evaluating supply chain scenarios. Wageningen, Wageningen University. Doctoral Thesis: 325.

Weaver, R.D., 2008. Collaborative Pull Innovation: Origins and Adoption in the New Economy. Agribusiness, 24: 388-402.

Wijnands, J.H.M., B.M.J. Van der Meulen and K. Poppe, 2007. Competitiveness of the European Food Industry. European Commission, Office for Official Publications of the European Community. Luxembourg.

Zeng, S.X., X.M. Xie and C.M. Tam, 2010. Relationship between cooperation networks and innovation performance of SMEs. Technovation, 30: 181-194. 
